\title{
Diagnostic criteria for computer-aided electrocardiographic 15-lead system Evaluation using 12 leads and Frank orthogonal leads with vector display
}

\author{
Stephen Talbot, Leonard S. Dreifus, Yoshio Watanabe, Robert Chiang, Kathryne Morris, \\ and Martin Reich
}

From the Department of Medicine, and the Department of Physiology and Biophysics, Hahnemann Medical College and Hospital, Philadelphia, Pennsylvania, USA

The criteria for the diagnosis of myocardial infarction and ischaemic heart disease by an automated 15-lead computer-aided electrocardiographic system were examined using electrocardiograms of 543 patients. Errors in the electrocardiographic diagnosis were evaluated for each lead system (Frank orthogonal 3-lead, 12-lead, and hybrid 15-lead) using clinical and catheterization data for definitive diagnosis before review of the electrocardiograms and their reports. The effects of combinations of these diagnoses and additional ventricular conduction defects were also studied.

Myocardial infarction and left ventricular hypertrophy were more reliably diagnosed using 3-lead and 12-lead systems together than with either system alone. The most sensitive criteria for anterior infarction were a $Q / R$ ratio in $Z<0 \cdot 1$ and loss of the first 20 ms of anterior forces in the horizontal and sagittal planes of the vectorcardiogram. However, false positive results were frequent, particularly in association with left ventricular hypertrophy, non-specific intraventricular conduction defects, and left bundle-branch system block. Our $V$ lead criteria were more specific whether or not these associated conditions were present. No single criterion with an acceptable false positive rate could be found to be sensitive for inferior infarction in all situations. Our most sensitive criteria were those based on the limb leads, and the presence of superior forces for the first $30 \mathrm{~ms}$ in the frontal plane of the vectorcardiogram, but these were better in combination. Limb lead criteria were the most specific. False positive results for inferior infarction were more frequent in the presence of left ventricular hypertrophy or ventricular conduction defects other than left anterior hemiblock.

$S T$ and $T$ wave abnormalities were more apparent in the 12 leads than in the orthogonal leads. Specificity and sensitivity of criteria were poor, and specificity was decreased and sensitivity was not significantly improved by combining 3-lead with 12-lead criteria. Because of frequent measurement errors of ST, $T$, and also $Q$ waves by the computer programme, in practice we have achieved increased sensitivity in the diagnosis of ischaemia and infarction with the combination of 3-lead and 12-lead systems.

It is concluded that errors of diagnosis by a computer-aided system can be reduced by using multiple leads and that both 12-lead and orthogonal 3-lead systems are necessary for optimal computer diagnosis of left ventricular hypertrophy, myocardial infarction, and ischaemia.

There is still controversy over the relative merits of 3-lead and 12-lead systems for computer electrocardiographic diagnosis (Caceres and Hochberg, 1970; Smith and Hyde, 1969; Bonner et al., 1972; Cornfield et al., 1973; Pordy et al., 1968). The orthogonal 3-lead system is the simplest to use for Received 2 February 1976. such analysis, but the 12 praecordial and limb leads are more familiar to physicians. Comparisons of waveform measurements have suggested that the orthogonal system provides nearly all the information obtained from the 12-lead system in normal people (MacFarlane, Lorimer, and Lawrie, 1971 ; Pipberger et al., 1961; Borun, Chapman, and 
Massey, 1966). Though some authors have found that the diagnostic accuracy of abnormalities of waveform is similar using the two systems (MacFarlane et al., 1971; Pipberger et al., 1961) others disagree (Bonner et al., 1972; Borun et al., 1966; Talbot et al., 1973), and in most studies 3-lead and 12-lead systems have been compared only in relation to specific diagnoses (Eddleman and Pipberger, 1971).

Talbot et al. (1973) reported their experience using both 3-lead and 12-lead systems. They found that a 15-lead electrocardiographic system and logic derived from all these leads gave the best results for myocardial infarction and right bundlebranch system block, and increased sensitivity for most diagnoses. In view of observer variation in electrocardiographic reporting (Davies, 1958), an objective method to confirm computer diagnoses is preferable (Yano and Pipberger, 1964). Using objective confirmation, Eddleman and Pipberger (1971) concluded that the Frank orthogonal 3-lead electrocardiogram was more sensitive and as accurate as the 12-lead electrocardiogram using Minnesota code classification (Blackburn et al., 1960) for the diagnosis of myocardial infarction. This code was designed for epidemiological studies and similar results may not be found with more sensitive 12-lead criteria.

We have, therefore, made a further comparison of orthogonal 3-lead, vectorcardiographic, and 12lead criteria, used in our 15-lead computer programme (Talbot et al., 1973). Necropsy and catheterization data provide the most accurate confirmation of electrocardiographic diagnoses. However, restriction of any study to diseases diagnosed by such methods will select those patients with more severe disease. We have used clinical information, supported by catheter data and a few necropsies, from men and women aged 40 to 80 years.

Multiple electrocardiographic abnormalities are frequent in clinical practice, and combinations of several abnormalities may have significance different from that of single ones. In this paper we have presented our results for patients with one or more myocardial infarcts, or myocardial ischaemia, alone or in combination. We have also examined the validity of these electrocardiographic criteria of infarction and ischaemia in the presence of left ventricular hypertrophy and ventricular conduction defects.

\section{Subjects and methods}

Electrocardiograms were obtained using an on-line automated electrocardiographic system, which has been previously described (Scheinok et al., 1972;
Talbot et al., 1973). Leads I, II, III, aVR, aVL, aVF, V1, V2, V3, V4, V5, and V6, and Frank $\mathrm{XYZ}$ leads were recorded simultaneously in groups of three leads. The three vector loops and the initial forces were obtained by digital-to-analogue conversion, displayed on an oscilloscope screen, and photographed with a high resolution camera. Electrocardiographic criteria were based on the 12 leads, the Frank XYZ leads, and the Frank vectorcardiogram, and hybrid criteria were formulated by combination of criteria from the three systems. However, not all statements were finally issued as an electrocardiographic report for clinical use. Some were suppressed by the computer but were preserved on a computer print-out. This enabled many different criteria and combinations of criteria to be assessed. Eighty-five per cent of all electrocardiograms recorded at Hahnemann Hospital are processed by computer.

Initially the scalar and vector electrocardiograms were examined to see whether the criteria in the programme for the diagnosis of myocardial infarction, left ventricular hypertrophy, or ischaemia, had been met. Frank 3-lead and 12-lead criteria were those in common use (Sokolow and Lyon, 1949; Allenstein and Mori, 1960; Sotobata, Richman, and Simonson, 1970; Chou and Helm, 1967; McConahay et al., 1970; Gunnar et al., 1967) and are presented in Table 1 which also includes vectorcardiographic criteria used in the hybrid programme.

We have already described our results in the diagnosis of conduction defects (Talbot et al., 1973). In this study the following definitions have been used.

1) Left bundle-branch system block: QRS duration $\geqslant 115 \mathrm{~ms}$ and intrinsicoid deflection in lead $X \geqslant 60 \mathrm{~ms}$; terminal $R$ waves without $Q$ waves in leads I or aVL.

2) Complete right bundle-branch system block: QRS duration $\geqslant 115 \mathrm{~ms}$; terminal $R^{\prime}$ wave in lead $\mathrm{V} 1$, and $\mathrm{R}^{\prime} \geqslant \mathrm{R}+0.2 \mathrm{mV}$.

Measurement of $\mathrm{QRS}$ duration was made in orthogonal leads, with limits based on the 95th centile of our normal population (Talbot et al., 1974). In fact, complete bundle-branch system blocks almost invariably showed a QRS duration $\geqslant 99$ th centile, i.e. $125 \mathrm{~ms}$.

3) Left anterior hemiblock: QRS axis between $-45^{\circ}$ and $-90^{\circ}$ if there were a $\mathrm{Q}$ wave in aVL (Rosenbaum, 1969). Usually this diagnosis was associated with a QRS duration $>90 \mathrm{~ms}$ (i.e. the lower limit of the 95th centile plus $20 \mathrm{~ms}$ ). The diagnosis of left anterior hemiblock was not made if the $R$ voltage in all limb leads was less than $0.5 \mathrm{mV}$. 
TABLE 1

\begin{tabular}{|c|c|c|c|c|}
\hline Diagnosis & 12-lead criteria $(A)$ & $\begin{array}{l}\text { Orthogonal/lead } \\
\text { criteria (B) }\end{array}$ & $\begin{array}{l}\text { Vectorcardiographic } \\
\text { criteria (C) }\end{array}$ & References \\
\hline $\begin{array}{l}\text { Anterior } \\
\text { infarction }\end{array}$ & $\begin{array}{l}R \text { waves }<0.1 \mathrm{mV} \\
\text { or } Q R \text { with } Q \geqslant 0.3 \mathrm{mV} \\
\text { in } 2 \text { leads of } V 2-V 4\end{array}$ & $Q / R$ ratio in $Z<0.1$ & $\begin{array}{l}\text { Loss of first } 20 \mathrm{~ms} \\
\text { anterior forces in } \\
\mathrm{XZ} \text { and } \mathrm{YZ} \text { planes }\end{array}$ & $\begin{array}{l}\text { (B) Eddleman and } \\
\text { Pipberger (1971) } \\
\text { (C) Chou and Helm } \\
(1967)\end{array}$ \\
\hline $\begin{array}{l}\text { Inferior } \\
\text { infarction }\end{array}$ & $\begin{array}{l}Q \text { waves } \geqslant 0.2 \mathrm{mV} \text { and } \\
30 \mathrm{~ms} \text { in } 2 \text { leads of II, } \\
\text { III, and aVF }\end{array}$ & $Q / R$ ratio in $Y \geqslant 0.25$ & $\begin{array}{l}\text { Superior forces for } \\
\text { first } 30 \mathrm{~ms}(-20 \text { to } \\
\left.-180^{\circ} \text { in XY plane }\right)\end{array}$ & $\begin{array}{l}\text { (B) Eddleman and } \\
\text { Pipberger (1971) } \\
\text { (C) Chou and Helm } \\
\text { (1967) }\end{array}$ \\
\hline $\begin{array}{l}\text { Lateral } \\
\text { infarction }\end{array}$ & $\begin{array}{l}\text { QR waves in V5 and V6 } \\
(Q \geqslant 0.3 \mathrm{mV}) \text { or } \\
R \leqslant 0.1 \mathrm{mV} \text { in these } \\
\text { leads }\end{array}$ & $Q / R$ ratio in $X \geqslant 0.20$ & & $\begin{array}{l}\text { (B) Modified from } \\
\text { Eddleman and } \\
\text { Pipberger (1971) }\end{array}$ \\
\hline $\begin{array}{l}\text { Left ventricular } \\
\text { hypertrophy }\end{array}$ & $\begin{array}{l}\mathrm{R} \text { V5 or V6+SV1 } \geqslant 3.7 \mathrm{mV} \\
\text { or } R \geqslant 2.7 \mathrm{mV} \text { in V5 or V6 } \\
\text { or } R \geqslant 1.6 \mathrm{mV} \text { in aVL }\end{array}$ & $\begin{array}{l}\text { Voltage of } R \text { or } S \text { wave } \\
>2 \cdot 2 \mathrm{mV} \text { in } \mathrm{X}, \mathrm{Y} \text { or } \mathrm{Z}\end{array}$ & $\begin{array}{l}\text { Maximum spatial } \\
\mathrm{QRS} \text { voltage }>2.0 \\
\mathrm{mV}\end{array}$ & $\begin{array}{c}\text { (A) Sokolow and Lyon } \\
(1949) \\
\text { (B) and (C) Chou and } \\
\text { Helm (1967); } \\
\text { Yano and } \\
\text { Pipberger (1964) }\end{array}$ \\
\hline $\begin{array}{l}\text { Anterior } \\
\text { ischaemia }\end{array}$ & $\begin{array}{l}\mathrm{T} \text { inversion in } \mathrm{V} 1 \text { to } \mathrm{V} 3 \text {, } \\
\text { or } \mathrm{V} 3 \text { and } \mathrm{V} 4 \text { ( } \mathrm{T} \text { equal to } \\
\text { or more negative than } \\
-0.1 \mathrm{mV} \text { ) }\end{array}$ & $\begin{array}{l}\mathrm{T} \text { inversion in } \mathrm{X} \text { ( } \mathrm{T} \text { equal } \\
\text { to or more negative } \\
\text { than }-0.1 \mathrm{mV} \text { ) } \\
\text { or } \mathrm{T} \text { upright and equal } \\
\text { to or more than } 0.2 \mathrm{mV} \\
\text { in } \mathrm{Z}\end{array}$ & & \\
\hline $\begin{array}{l}\text { Anterolateral } \\
\text { ischaemia }\end{array}$ & $\begin{array}{l}\mathrm{T} \text { inversion in } \mathrm{V} 5 \text { and } \mathrm{V} 6 \\
\text { ( } \mathrm{T} \text { equal to or more } \\
\text { negative than }-0.1 \mathrm{mV} \text { ) } \\
\text { or } \mathrm{T} \text { wave inversion of } \\
\text { more than } 0.2 \mathrm{mV} \text { in } \\
\text { either V5 or V6 }\end{array}$ & $\begin{array}{l}\mathrm{T} \text { inversion equal to or } \\
\text { more than } 0.2 \mathrm{mV} \text { in } \mathrm{X}\end{array}$ & & \\
\hline $\begin{array}{l}\text { Inferior } \\
\text { ischaemia }\end{array}$ & $\begin{array}{l}\mathrm{T} \text { inversion of more than } \\
0.1 \mathrm{mV} \text { in } 2 \text { leads of } \\
\text { II, III, or aVF }\end{array}$ & $\begin{array}{l}\mathrm{T} \text { inversion equal to or } \\
\text { more than } 0.2 \mathrm{mV} \text { in } \mathrm{Y}\end{array}$ & & \\
\hline $\begin{array}{l}\text { ST displacement } \\
(+ \text { or }-v e)\end{array}$ & $\begin{array}{l}\text { Difference of } \geqslant 0.15 \mathrm{mV} \text { in } \\
\text { ST compared with } \\
\text { baseline }\end{array}$ & $\begin{array}{l}\text { Difference of } \geqslant 0.15 \mathrm{mV} \\
\text { in ST compared with } \\
\text { baseline }\end{array}$ & & \\
\hline
\end{tabular}

4) Intraventricular conduction delay: QRS duration $\geqslant 115 \mathrm{~ms}$, with no other criteria for bundlebranch system block.

Combined (hybrid) criteria for inferior and anterior infarction are described in Appendix A. If criteria from the 3 orthogonal leads or the vectorcardiogram or the 12 leads were fulfilled, this was described as 'or-logic'; and if criteria from either the 3 orthogonal leads or the vectorcardiogram, together with criteria from the 12 leads, were fulfilled, this was described as 'and-logic' (Talbot et al., 1973). Therefore, 'and-logic' required criteria from two or more of the three systems to be fulfilled. Diagnoses were assigned qualitative probability but for this study the definite, 'probable', and 'possible' reports have been amalgamated.

All electrocardiograms recorded during a sevenweek period were selected for inclusion in this study, if reported by the computer (using either 3-lead, 12-lead, or hybrid criteria) to show inferior or anterior infarction, left ventricular hypertrophy, left or right bundle-branch system block, left anterior hemiblock, a non-specific intraventricular conduction defect, or any combination of these. Some electrocardiograms selected had been included in a previous study (Talbot et al., 1973). Electrocardiograms were examined only after a complete medical record had been obtained and the clinical diagnosis determined by criteria outlined in Appendix B. In this study 961 electrocardiograms (165 men and 94 women) were examined. The diagnosis was confirmed at necropsy in 4 patients, coronary arteriography in 25 , and cardiac catheterization and operation in 19. Such a study cannot include all electrocardiograms with false negative diagnoses.

To avoid this bias in favour of computer criteria, we examined the final diagnosis for each patient in hospital during this period; if the diagnosis were myocardial infarction or if a cause for left ventricular hypertrophy could be established (see Appendix B) the electrocardiograms were examined. This group 
comprised 908 electrocardiograms from 112 men and 70 women. For analysis of myocardial ischaemia, we examined an additional 289 electrocardiograms from 102 patients coded as ischaemic heart disease (400-404 and 410, International Classification of Diseases, 8th Revision, 1967-1969) and confirmed by coronary angiography.

Each electrocardiogram was examined for diagnostic features of myocardial infarction, left ventricular hypertrophy, and ischaemia (Table 1). These features included all the criteria, including the hybrid criteria described. From this analysis computer measurement errors were identified and all other errors of diagnosis in relation to the clinical diagnosis were described as criteria errors. In all, 1869 electrocardiograms of 441 patients were examined for accuracy of diagnostic statements of myocardial infarction and left ventricular hypertrophy and 2158 electrocardiograms (543 patients) were examined for ST and T wave abnormalities. The latter were divided into ST segment depression and ST segment elevation, specific $T$ wave abnormalities of ischaemia as detailed in Table 1, and non-specific $T$ wave abnormalities, consisting of all $T$ wave abnormalities in any one of the 12 leads, and $T$ waves of $0.1 \mathrm{mV}$ or less in multiple leads, or $\mathrm{X}, \mathrm{Y}$, or $\mathrm{Z}$, which could not be described as diagnostic of ischaemia.

The majority of errors of diagnosis were criteria errors. Separate analysis of the results from the three groups of electrocardiograms did not lead to any different conclusions, and the results have therefore been amalgamated. Only the 12-lead, orthogonal 3-lead, and vectorcardiographic criteria that were found most satisfactory have been presented.

In this study we have clearly distinguished between false positive criteria and false positive measurement errors, but have not detailed false negative results because of our inability to localize the areas of ischaemia or infarction by coronary arteriography.

\section{Results}

The results of anterior and inferior infarction criteria are shown in Table 2. Myocardial infarction

TABLE 2 Comparison of diagnostic criteria for myocardial infarction

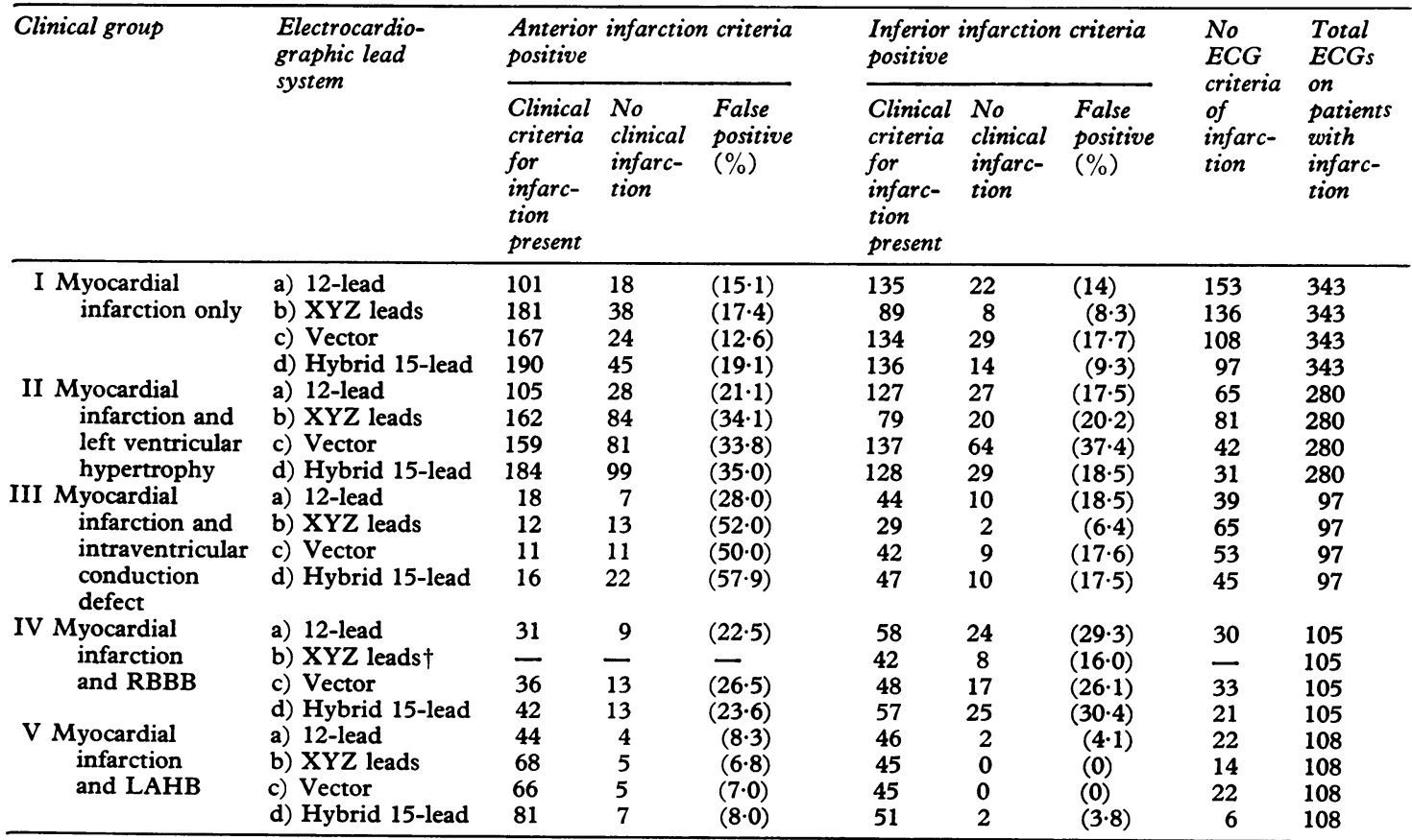

$\star$ Excluding measurement errors.

Percentages of false positive diagnoses were calculated in relation to electrocardiographic diagnoses and are shown in parentheses. Details of criteria are in Table 1 and Appendix A.

tOrthogonal criteria for anterior infarction and right bundle-branch block are not presented because of the low $R$ wave voltage of $Z$ and therefore inaccurate values of $Q / R$ ratio in $Z$.

Abbreviations : $\mathrm{RBBB}=$ right bundle-branch block; $\mathrm{LAHB}=$ left anterior hemiblock. 
is often present even when electrocardiographic features are not. We have, therefore, concluded that the criterion most often found in association with clinical evidence of infarction was the most sensitive sign of infarction in this area. Criteria were often fulfilled for different localizations of infarction in the same patient using different systems; for this reason separate analysis of anterior

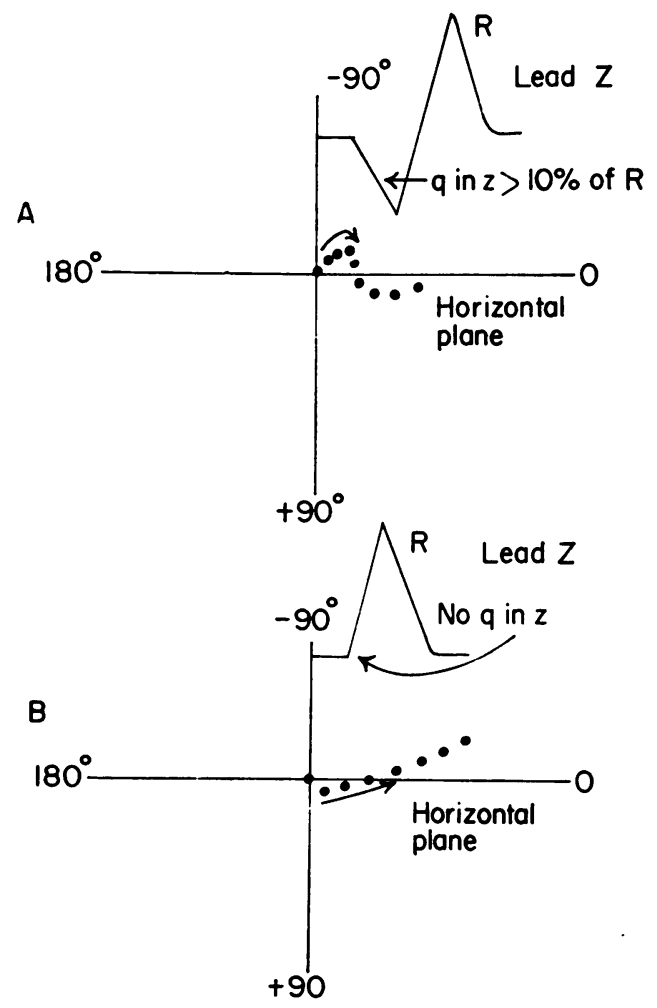

FIG. 1 Diagrammatic representation of the initial $40 \mathrm{~ms}$ forces of the horizontal plane of the vectorcardiogram and lead $Z$ of the Frank electrocardiogram. (A) The initial $20 \mathrm{~ms}$ forces of the vectorcardiogram are directed posteriorly and yet $Q / R$ ratio is normal. No initial $R$ wave was detected by the computer or the cardiologist though a small $R$ wave must have been present simultaneously with the initial $20 \mathrm{~ms}$ forces of the vectorcardiogram. (B) The initial $10 \mathrm{~ms}$ forces of the vectorcardiogram are slightly anterior but the later forces are posterior. No $Q$ wave in lead $Z$ was detected by the computer or the cardiologist though a small $Q$ wave must have been present simultaneously with the initial $10 \mathrm{~ms}$ forces of the vectorcardiogram. and inferior criteria together, anterior criteria alone, and inferior criteria alone would be misleading.

\section{Anterior myocardial infarction}

The most sensitive criterion for anterior infarction was a $Q / R$ ratio in $Z<0 \cdot 1$, but loss of anterior forces in the sagittal and horizontal planes of the vectorcardiogram was almost as sensitive. Computer hybrid criteria were even more sensitive, because of occasional discrepancies between these two diagnostic criteria. In some infarctions (Fig. 1A) there was early posterior orientation of initial forces for $20 \mathrm{~ms}$ (XZ plane), which then turned sharply forward so that the $Q / R$ ratio in $Z$ was preserved, whereas in others the first $10 \mathrm{~ms}$ forces were anterior though the next $20 \mathrm{~ms}$ forces were posterior (Fig. 1B). Early posterior orientation of horizontal forces was often associated with a narrow $R$ wave in V1 to V3. Occasionally the only positive indication of old anterior infarction was a $Q$ wave of $0.1 \mathrm{mV}$ and less than $20 \mathrm{~ms}$ duration in two of the three leads V2, V3, and V4, but an isolated small $Q$ wave in the transition zone was not significant. Associated left ventricular hypertrophy produced more falsepositive results, particularly with orthogonal and vectorcardiographic criteria, but there were few electrocardiograms of patients with infarction in which the diagnosis was not suggested by 15 leads (Fig. 2).

Left bundle-branch system block was found in only 20 electrocardiograms of patients with infarction; though a hybrid 15-lead diagnosis of anterior infarction was correctly made in 17 electrocardiograms, there were $48(73.8 \%)$ false-positive results, mainly because of vectorcardiographic and orthogonal criteria. Q waves rarely spread to V4 in the absence of infarction. Right bundle-branch system block was not associated with significantly more false-positive results, but $Q$ waves in V1 to V3 were sometimes falsely detected, probably because of the low voltage of the initial $R$ wave. The $R$ wave in lead $\mathrm{Z}$ is often of low voltage in right bundlebranch system block, so that in our experience the $Q / R$ ratio in $Z$ is not satisfactory in this condition. However, the absence of a $Q$ in $Z$ is an indication of anterior myocardial infarction. Right bundle-branch system block was particularly associated with $Q R$ complexes in V1 to V4, but $Q R$ complexes were of more significance than QS waves in all conditions except in V4. Left anterior hemiblock did not appear to affect the diagnosis of anterior infarction. Nonspecific intraventricular conduction defects reduced the specificity of all criteria for anterior infarction and sensitivity may also have been reduced. 


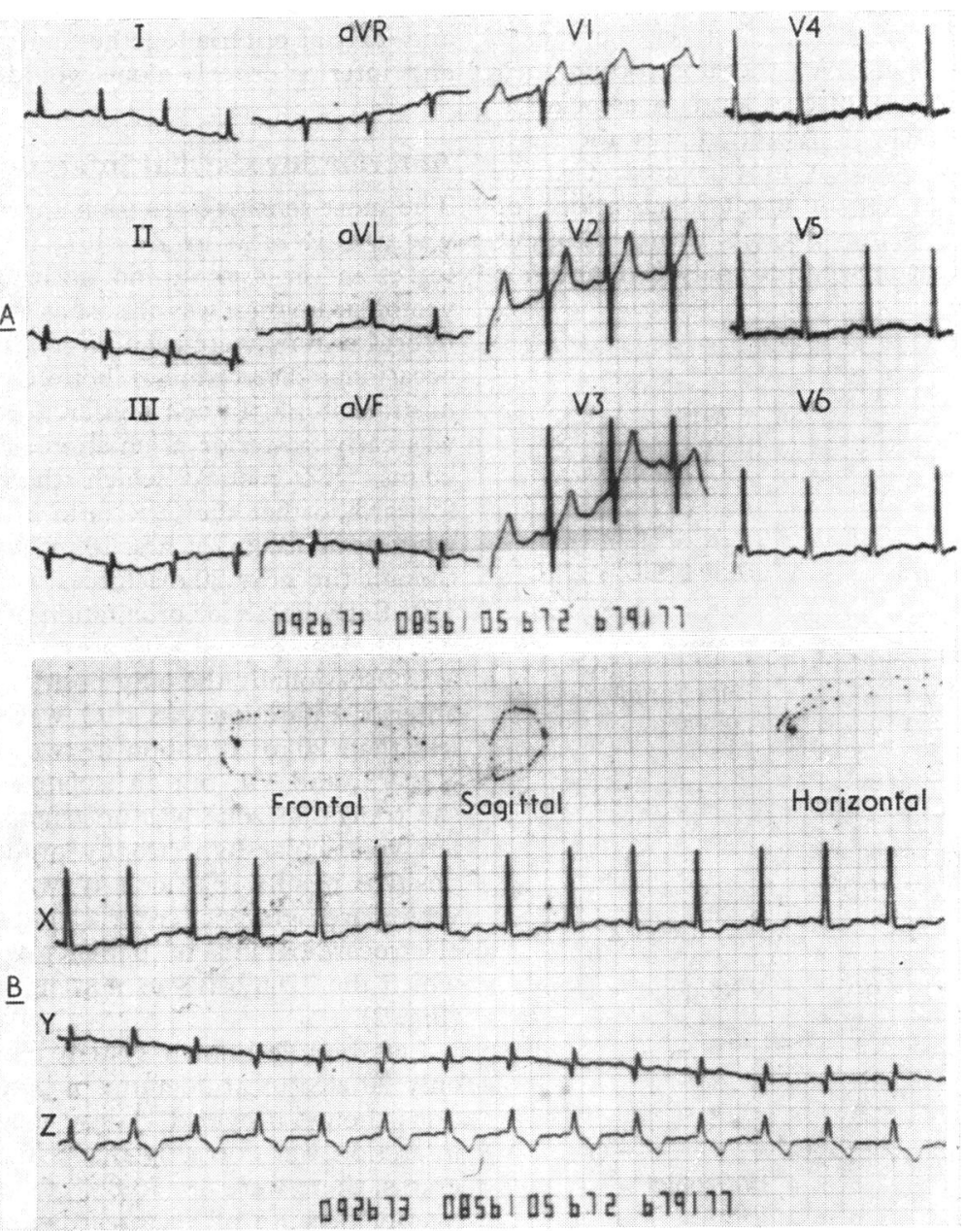

FIG. 2 Electrocardiograms and vectorcardiographic loops of a 52-year-old man. Serial records had shown the development of inferior and true posterior infarction, with a prominent $R$ wave in $V 1$ and V2. There was clinical evidence of myocardial infarction initially and further infarction developed six months later. (A) The 12-lead electrocardiogram at this time is shown. This did not show any significant change from the earlier record. (B) Vectorcardiogram and orthogonal leads. Above, from left to right: frontal, sagittal, and horizontal plane vector loops. Below, orthogonal leads $X, Y$, and $Z$. Both the $Q$ wave in $Z$ and anterior forces were lost, compared with the electrocardiogram taken six months earlier. The rightward orientation of the initial forces probably indicates lateral infarction as well. These changes persisted, and show the value of Frank 3 leads for the sensitive diagnosis of anterior myocardial infarction.

\section{Inferior myocardial infarction}

The most sensitive of the selected single-lead criteria for inferior infarction was the presence of a $Q$ wave in lead aVF of $\geqslant 0.2 \mathrm{mV}$. In fact $Q$ waves of $0.1 \mathrm{mV}$ were even more sensitive and $Q$ waves of $0.1 \mathrm{mV}$ in leads II, III, and aVF were usually associated with clinical infarction. Loss of inferior forces was also a sensitive criterion but, as with $Q$ in lead III alone, produced an unacceptable number of false-positive results, particularly in the presence of left ventricular hypertrophy. False negative results occurred in typical inferior infarction when there was associated lateral infarction in which initial forces in the frontal plane were sometimes diverted to the right and slightly inferiorly, 

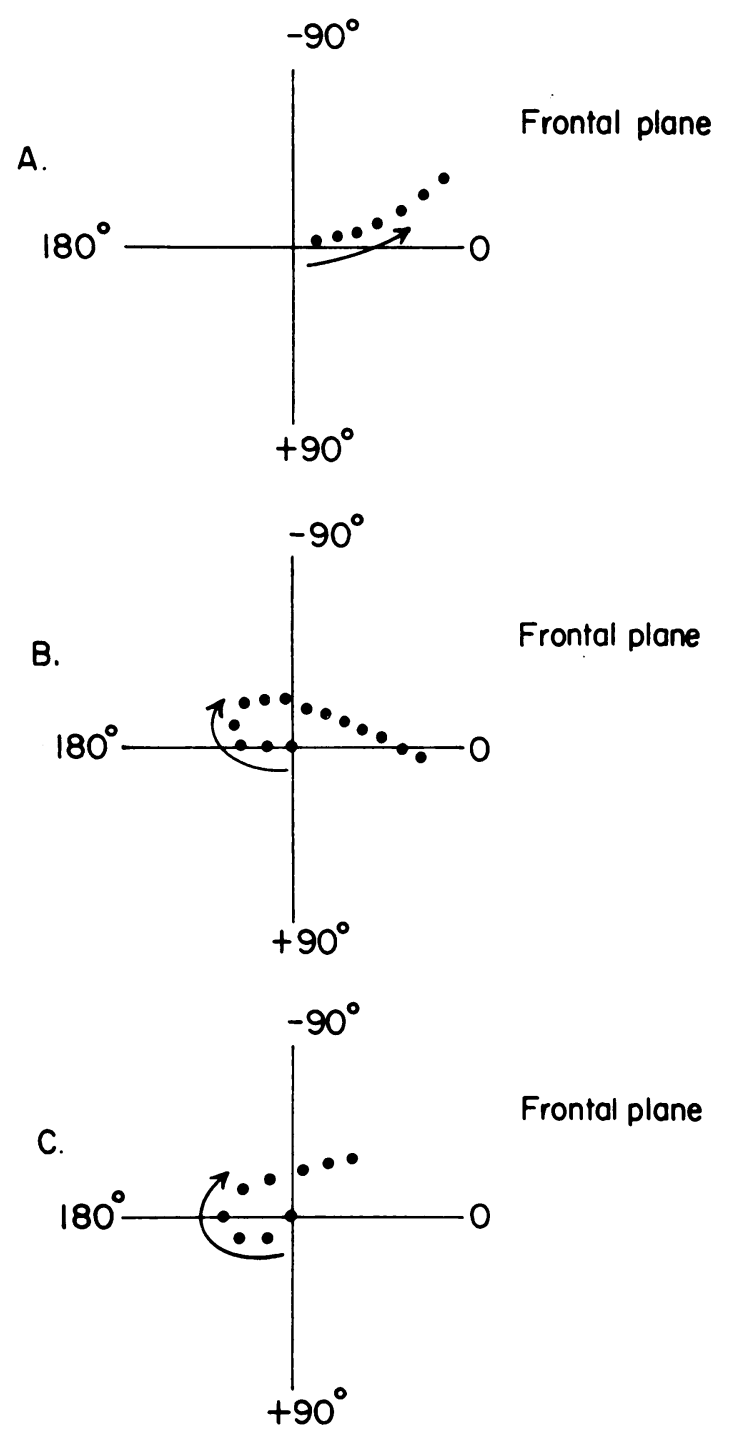

Frontal plane

Frontal plane

FIG. 3 Frontal plane vectors in inferior infarction (5 ms interval markers). (A) The initial forces are directed superiorly and to the left at $-20^{\circ}$ with counterclockwise rotation. However, there is distinct left axis deviation. (B) The initial $10 \mathrm{~ms}$ forces are horizontal but the rotation of the loop is clockwise and the axis is horizontal. (C) The initial $10 \mathrm{~ms}$ forces are directed inferiorly and to the right before turning clockwise and to the left. The axis is usually horizontal. The first configuration may or may not be associated with inferior infarction; the latter two usually are associated with inferior infarction. but $\mathrm{Q}$ waves were present in leads II and aVF (or Y) (Fig. 3).

Left ventricular hypertrophy was associated with superior forces for the initial $30 \mathrm{~ms}$ when the frontal plan QRS axis was vertical $\left(\geqslant+45^{\circ}\right)$ in the absence of infarction; this increased the number of false-positive results for inferior infarction in all lead systems. In the presence of left bundle-branch system block and left anterior hemiblock (or left axis deviation), $R$ waves were often small in the absence of infarction and $Q$ waves occasionally appeared in III and aVF but not in II. Falsepositive results were common in the presence of combined right bundle-branch system block and left anterior hemiblock, probably because a very small initial $R$ wave was not detected; this was followed by a conspicuous $S$ wave before the terminal $\mathbf{R}^{\prime}$ wave in III and aVF. The vectorcardiogram was often necessary to confirm initial inferior forces. Non-specific intraventricular conduction defects were commonly found in association with criteria of inferior infarction and slightly increased false-positive results.

\section{Optimal computer criteria for infarction}

Hybrid computer criteria were the most sensitive for anterior and inferior infarction, and the presence of specific criteria resulting in a diagnosis of probable or definite infarction correlated well with the clinical diagnosis. The most specific criteria for inferior and anterior infarction have been tested (Table 3) so that diagnoses can be assigned a degree of probability. Loss of specificity for anterior infarction resulted from inclusion of the $Q$ wave in V3 without $Q$ in V4, particularly in association with left ventricular hypertrophy and intraventricular conduction defects, and there was loss of specificity for inferior infarction with reduction of $Q / R$ ratios. We noted that $Q / R$ ratios were valid even with $Q$ waves of $0.1 \mathrm{mV}$, when a $\mathrm{W}$-shaped complex was often seen. The $Q$ wave in III added little that could not be obtained from aVF alone, and a $\mathrm{Q}$ wave $\geqslant 0.2 \mathrm{mV}$ in lead aVF was only slightly more specific and less sensitive than the 12-lead combined criteria of the computer programme. However, the additional presence of a Q wave of $\geqslant 0.2 \mathrm{mV}$ in II, particularly if the $Q / R$ ratio $\geqslant 25$ per cent, considerably enhanced the specificity of a $Q$ wave in III or aVF. Even a $Q$ wave of $0.1 \mathrm{mV}$ in II was supportive evidence for other criteria of inferior infarction. $A Q / R$ ratio in $I I$, III, and aVF of over 0.25 was almost diagnostic of inferior infarction, and was associated with a rightward and superior direction of the initial $30 \mathrm{~ms}$ forces in the frontal plane. 
TABLE 3 Specific diagnostic criteria ${ }^{\star}$

\begin{tabular}{|c|c|c|c|c|c|c|c|c|c|}
\hline & $\begin{array}{l}\text { Positive cr } \\
Q / R \text { in } \\
I I+I I I+ \\
a V F \\
\geqslant 0.25\end{array}$ & $\begin{array}{l}\text { iteria for in } \\
Q / R \text { in } \\
I I+a V F \\
\geqslant 0.25\end{array}$ & $\begin{array}{l}\text { erior infarct } \\
Q W \text { aves in } \\
I I+I I I+ \\
a V F \\
\geqslant 0.2 m v\end{array}$ & $\begin{array}{l}{\underset{\text { in }}{Q}}^{\star \star} \text { Waves } \\
I I+a V F \\
\geqslant 0.2 \mathrm{mv}\end{array}$ & $\begin{array}{l}\text { Positive c } \\
Q \text { Waves } \\
\text { in } \\
\text { 2-V4 }\end{array}$ & $\begin{array}{l}\text { iteria for a } \\
\underset{\text { in }}{W} \\
V 3+V 4 e s \\
\end{array}$ & $\begin{array}{l}\text { terior infar } \\
\underset{\text { in }}{Q} \text { Waves } \\
V 4\end{array}$ & $\begin{array}{l}\underset{\text { inon }}{Q}{ }_{\text {in }}^{\star} \\
V 2+V 3\end{array}$ & $\begin{array}{l}\underset{\text { in }}{Q} \text { Waves } \\
V 3\end{array}$ \\
\hline $\begin{array}{l}\text { Clinical criteria for } \\
\text { infarction present } \\
\text { False positive } \dagger\end{array}$ & $\begin{array}{l}181 \\
15(7 \cdot 7)\end{array}$ & $\begin{array}{l}186 \\
17(8 \cdot 4)\end{array}$ & $\begin{array}{l}299 \\
30(9 \cdot 1)\end{array}$ & $\begin{array}{l}314 \\
39(11 \cdot 0)\end{array}$ & $\begin{array}{l}146 \\
12(7 \cdot 6)\end{array}$ & $\begin{array}{l}213 \\
20(8 \cdot 6)\end{array}$ & $\begin{array}{l}223 \\
22(9 \cdot 0)\end{array}$ & $\begin{array}{l}277 \\
63(18 \cdot 5)\end{array}$ & $\begin{array}{l}315 \\
68(17 \cdot 8)\end{array}$ \\
\hline
\end{tabular}

*Excluding patients with left bundle-branch block. Total number of electrocardiograms examined $=933$.

$\star \star$ Less specific criteria are not shown. Specificity increases from right to left for both inferior and anterior infarction criteria.

$\dagger$ Percentage of false positives in parentheses.

\section{Lateral infarction}

Criteria for lateral infarction were only fulfilled in $15 \cdot 2$ per cent of cases with myocardial infarction. Though the presence of $Q$ waves in leads V5 and V6 together did decrease sensitivity, this combination was still superior to the $Q / R$ ratio $\geqslant 0.20$ in $X$. No example of high lateral infarction with changes confined to leads I and aVL or high praecordial leads was noted during this study. During the period of the study, 11 electrocardiograms (2 patients) were found in which criteria for lateral infarction only were satisfied; in these electrocardiograms the V-lead criteria were superior to $\mathbf{Q} / \mathbf{R}$ ratio in lead $\mathbf{X}$.

\section{Myocardial ischaemia}

$S T$ and $T$ wave criteria errors in 3-lead and 12lead electrocardiograms are shown in Table 4. A separate analysis of $T$ wave abnormalities for each

TABLE 4 Diagnostic accuracy of ST and T wave criteria for ischaemia

\begin{tabular}{|c|c|c|c|c|c|}
\hline \multirow[t]{2}{*}{ Electrocardiographic diagnosis } & \multirow[t]{2}{*}{ Clinical diagnosis } & \multicolumn{2}{|c|}{ No other abnormality } & \multicolumn{2}{|c|}{ Left ventricular hypertrophy } \\
\hline & & $X Y Z$ & 12-lead & $X Y Z$ & 12-lead \\
\hline $\begin{array}{l}\text { *Anterolateral ischaemia } \\
\mathrm{T} \text { inversion } \mathrm{V} 5 \text { and } \mathrm{V} 6\end{array}$ & $\begin{array}{l}\text { Clinical and electro- } \\
\text { cardiographic positive }\end{array}$ & 184 & 209 & 84 & 99 \\
\hline $\begin{array}{l}\mathrm{T} \text { inversion in } \mathrm{X} \\
\star \text { Anterior ischaemia }\end{array}$ & False positive criteria $\dagger$ & $9(4 \cdot 7)$ & $10(4 \cdot 6)$ & $259(75 \cdot 5)$ & $269(73 \cdot 1)$ \\
\hline $\begin{array}{l}\mathrm{T} \text { inversion in any } 2 \text { leads of } \\
\mathrm{V} 2 \text { to } \mathrm{V} 4\end{array}$ & $\begin{array}{l}\text { Clinical and electro- } \\
\text { cardiographic positive }\end{array}$ & 12 & 24 & 8 & 19 \\
\hline $\begin{array}{l}\mathrm{T} \text { upright in } \mathrm{Z}, \mathrm{T} \text { inversion in } \mathrm{X} \\
\text { *Inferior ischaemia }\end{array}$ & False positive criteria $\dagger$ & $0(0)$ & $0(0)$ & $0(0)$ & $0(0)$ \\
\hline $\begin{array}{l}T \text { inversion in any } 2 \text { leads of } \\
\text { II, III, aVF }\end{array}$ & $\begin{array}{l}\text { Clinical and electro- } \\
\text { cardiographic positive }\end{array}$ & 70 & 92 & 30 & 42 \\
\hline $\begin{array}{l}\mathrm{T} \text { inversion in } \mathrm{Y} \\
\text { Inferior } S T \text { depression }\end{array}$ & False positive criteria $†$ & $0(0)$ & $0(0)$ & $41(57 \cdot 7)$ & $44(51 \cdot 2)$ \\
\hline $\begin{array}{l}\text { ST depression in any } 2 \text { leads of } \\
\text { II, III, aVF }\end{array}$ & $\begin{array}{l}\text { Clinical and electro- } \\
\text { cardiographic positive }\end{array}$ & 7 & 13 & 8 & 16 \\
\hline $\begin{array}{l}\text { ST depression in } \mathrm{Y} \\
\text { Anterior } S T \text { depression }\end{array}$ & False positive criteria $\dagger$ & $0(0)$ & $0(0)$ & $11(57 \cdot 9)$ & $22(57 \cdot 9)$ \\
\hline $\begin{array}{l}\text { ST depression in any } 2 \text { leads of } \\
\text { V2 to V6 }\end{array}$ & $\begin{array}{l}\text { Clinical and electro- } \\
\text { cardiographic positive }\end{array}$ & & 86 & 67 & \\
\hline $\begin{array}{l}S T \text { depression in } \mathrm{X} \\
S T \text { elevation }\end{array}$ & False positive criteria $\dagger$ & $3(4 \cdot 1)$ & $6(6 \cdot 5)$ & $149(69 \cdot 0)$ & $168(68.9)$ \\
\hline $\begin{array}{l}\text { ST elevation in any } 2 \text { leads of } \\
\text { V1 to V6 }\end{array}$ & $\begin{array}{l}\text { Clinical and electro- } \\
\text { cardiographic positive }\end{array}$ & & 59 & 6 & 9 \\
\hline $\begin{array}{l}\text { ST elevation in } \mathrm{X} \\
\text { Non-specific } T \text { wave changes }\end{array}$ & False positive criteria $\dagger$ & $\begin{array}{l}1(2 \cdot 1) \\
234\end{array}$ & $\begin{array}{l}0(0) \\
240\end{array}$ & $\begin{array}{l}2(25) \\
179\end{array}$ & $\begin{array}{l}2(18 \cdot 4) \\
152\end{array}$ \\
\hline $\begin{array}{l}\text { Normal } T \text { waves } \\
\text { Total number of electrocardiograms }\end{array}$ & th ischaemia & 119 & 79 & 316 & 18 \\
\hline
\end{tabular}

* Some patients showed both inferior and anterior $S T$ and $T$ wave changes, see Table 1 and text for full criteria. $\dagger$ Percentages of false-positive results are in parentheses. 
conduction defect was performed, and since $T$ wave abnormalities in the presence of left bundle-branch system block did not appear to be of diagnostic value, they have been excluded from this table. ST depression and $T$ wave changes were not specific for ischaemia even if there were normal intraventricular conduction and no evidence of left ventricular hypertrophy. Specificity of $T$ wave inversion and ST depression in both 3-lead and 12-lead electrocardiograms was reduced in the presence of left ventricular hypertrophy, particularly if there were electrocardiographic features of left ventricular hypertrophy. Sensitivity was greater for the 12-lead than for 3-lead criteria, and this was out of proportion to the slightly greater diagnostic specificity of our 3-lead criteria for anterior ischaemia. The 3-lead criteria of this programme were particularly insensitive to anterior without lateral ischaemic changes, and better 3-lead criteria must be devised. False-positive results for anterior ischaemia occur in the presence of right bundlebranch system block, since $T$ wave inversion, sometimes with ST depression, can extend as far as V3 in the absence of ischaemia, and this state-

\begin{tabular}{|c|c|c|c|}
\hline \multicolumn{2}{|c|}{$\begin{array}{l}\text { Left ventricular hypertrophy } \\
\text { and any ventricular } \\
\text { conduction defect }\end{array}$} & \multicolumn{2}{|c|}{$\begin{array}{l}\text { Any ventricular } \\
\text { conduction defect alone }\end{array}$} \\
\hline$X Y Z$ & 12-lead & $X Y Z$ & 12-lead \\
\hline $\begin{array}{l}18 \\
52(74 \cdot 3)\end{array}$ & $\begin{array}{l}24 \\
67(73 \cdot 6)\end{array}$ & $\begin{array}{l}29 \\
65(69 \cdot 1)\end{array}$ & $\begin{array}{l}32 \\
76(70 \cdot 9)\end{array}$ \\
\hline $\begin{array}{l}13 \\
4(23 \cdot 5)\end{array}$ & $\begin{array}{l}18 \\
12(40 \cdot 0)\end{array}$ & $\begin{array}{l}13 \\
5(27 \cdot 8)\end{array}$ & $\begin{array}{l}25 \\
18(41 \cdot 8)\end{array}$ \\
\hline $\begin{array}{l}9 \\
9(50 \cdot 0)\end{array}$ & $\begin{array}{l}11 \\
10(47 \cdot 6)\end{array}$ & $\begin{array}{l}18 \\
3(14 \cdot 3)\end{array}$ & $\begin{array}{l}24 \\
4(14 \cdot 3)\end{array}$ \\
\hline $\begin{array}{l}4 \\
2(33 \cdot 3)\end{array}$ & $\begin{array}{l}5 \\
2(28 \cdot 6)\end{array}$ & $\begin{array}{l}2 \\
15(8 \cdot 8)\end{array}$ & $\begin{array}{l}2 \\
16(8 \cdot 9)\end{array}$ \\
\hline $\begin{array}{l}48 \\
75(61 \cdot 0)\end{array}$ & $\begin{array}{l}52 \\
90(63 \cdot 4)\end{array}$ & $\begin{array}{l}47 \\
78(62 \cdot 4)\end{array}$ & $\begin{array}{l}57 \\
87(60 \cdot 4)\end{array}$ \\
\hline $\begin{array}{l}4 \\
0(0) \\
87 \\
1\end{array}$ & $\begin{array}{l}5 \\
0(0) \\
80 \\
0\end{array}$ & $\begin{array}{l}1 \\
0(0) \\
100 \\
20\end{array}$ & $\begin{array}{l}1 \\
0(0) \\
83 \\
16\end{array}$ \\
\hline
\end{tabular}

ment is suppressed by the computer. ST segment depression, particularly in inferior leads, was moderately specific for ischaemia in the absence of left ventricular hypertrophy, non-specific intraventricular conduction defects, or right bundlebranch block. It was noted that $T$ wave inversion without ST segment depression was of greater diagnostic value for ischaemia than similar $T$ wave inversion with ST segment depression in the presence of left ventricular hypertrophy, nonspecific intraventricular conduction defects, or right bundle-branch block. Inferior ST and $T$ wave changes were more specific than those in V5 and V6, but they were less frequent. There were rarely normal $T$ waves in the presence of ischaemic heart disease and left ventricular hypertrophy. ST elevation was specific for ischaemia in all conditions.

\section{Measurement errors}

Errors of measurement of QRS, which resulted in false positive diagnoses of myocardial infarction occurred sometimes in the 12-lead system and sometimes in the orthogonal lead system and vectorcardiogram. An irregular baseline, as with atrial fibrillation or flutter or technical difficulties, was an important cause of error particularly affecting measurement of the $Q$ wave. Because of discrepancies between these systems the 15-lead system led to improvement in sensitivity of diagnosis.

Measurement errors of the ST segment and T wave in a sub-sample of 786 electrocardiograms compared with the cardiologist's interpretation are shown in Table 5. Orthogonal leads were not only less sensitive to $S T$ and $T$ wave changes, but there were as many errors of measurement in this system as in the $\mathrm{V}$ leads. The computer programme failed to detect ST changes in both 12 leads and orthogonal leads and there were both false-positive and false-negative results for $T$ wave changes. Occasionally ST elevation or depression was incorrectly reported. The principal discrepancy between orthogonal and 12-lead systems was $T$ wave inversion in V1 to V4 (anterior ischaemia); this abnormality was often not visible in orthogonal leads. Occasionally this V-lead diagnosis was made incorrectly in the presence of a negative QRS and a pronounced upwards ST slope merging into the $T$ wave, when the latter part of the positive $\mathrm{T}$ wave was considered to be inverted in these leads by the computer.

\section{Discussion}

Most studies of orthogonal, vectorcardiographic, and 12-lead criteria have been concerned with the 
TABLE 5 Accuracy of computer diagnosis of $S T$ and $T$ wave changes (measurement errors)*

\begin{tabular}{|c|c|c|c|c|c|c|c|c|}
\hline $\begin{array}{l}\text { Electrocardiographic } \\
\text { diagnosis }\end{array}$ & $\begin{array}{l}X Y Z \text { leads } \\
\text { Total } \\
\text { number of } \\
\text { cardiologist's } \\
\text { statements }\end{array}$ & $\begin{array}{l}\text { Computer } \\
\text { and } \\
\text { cardiologist } \\
\text { positive }\end{array}$ & $\begin{array}{l}\text { False } \\
\text { positive } \\
\text { computer } \\
\text { diagnosis } \dagger\end{array}$ & $\begin{array}{l}\text { False } \\
\text { negative } \\
\text { computer } \\
\text { diagnosis }\end{array}$ & $\begin{array}{l}12 \text { leads } \\
\text { Total } \\
\text { number of } \\
\text { cardiologist's } \\
\text { statements }\end{array}$ & $\begin{array}{l}\text { Computer } \\
\text { and } \\
\text { cardiologist } \\
\text { positive }\end{array}$ & $\begin{array}{l}\text { False } \\
\text { positive } \\
\text { computer } \\
\text { diagnosis } \dagger\end{array}$ & $\begin{array}{l}\text { False } \\
\text { negative } \\
\text { computer } \\
\text { diagnosis }\end{array}$ \\
\hline Anterolateral ischaemia & 225 & 198 & $3(1.5)$ & 27 & 255 & 222 & $4(1 \cdot 8)$ & 33 \\
\hline Inferior ischaemia & 77 & 64 & $3(4 \cdot 5)$ & 13 & 103 & 79 & $2(2 \cdot 5)$ & 24 \\
\hline Anterior ischaemia & 22 & 21 & $0(0)$ & 1 & 40 & 34 & $1(2 \cdot 9)$ & 16 \\
\hline \multicolumn{9}{|l|}{ Anterior or inferior } \\
\hline ST elevation & 50 & 20 & $0(0)$ & 30 & 61 & 22 & $2(8 \cdot 3)$ & 39 \\
\hline Anterior ST depression & 164 & 129 & $8(5 \cdot 8)$ & 35 & 213 & 168 & $11(6 \cdot 1)$ & 35 \\
\hline Inferior ST depression & 10 & 9 & $1(10)$ & 1 & 22 & 18 & $1(5 \cdot 3)$ & 4 \\
\hline Non-specific $T$ changes & 326 & 235 & $2(0.8)$ & 91 & 315 & 231 & $2(0.4)$ & 84 \\
\hline
\end{tabular}

*The computer statement has been compared with the cardiologist's interpretation using the same criteria as produced the computer statement.

†Percentage false positive statements, in parentheses, are expressed in relation to the number of positive electrocardiographic diagnoses by computer.

diagnostic accuracy of such criteria, using various mathematical methods (Simonson, 1961), which assign equal importance to false-positive and falsenegative results. However, in epidemiological and clinical work, requirements may differ, and statements of both specificity and sensitivity may be necessary.

The sensitivity of any test is measured by the percentage of people with the disease under consideration, who are correctly classified by the test. Specificity is calculated from the percentage of people without the disease, who have a negative result to the test. Sensitivity is affected by the population examined. Mildly affected patients may not be subjected to the test, and test records of more severe cases may not be obtainable for logistic or humanitarian reasons. Also, specificity (by the definition given) is greatly affected by the variety of clinical conditions in the population which are frequently confused with the diagnosis under investigation. A more useful measurement is the predictability of the test, i.e. the percentage of correct positive diagnoses by the test in relation to the total number of positive tests. The predictability of the electrocardiographic criteria and the percentage of false-positive results have been measured in this study, but this is only related to specificity in the hospital population examined and might not be applicable in other situations.

Myocardial infarction cannot be localized without pathological or electrocardiographic information, and therefore false-positive results may actually be higher than indicated. We cannot determine the frequency of false-negative electrocardiographic diagnoses without necropsy evidence. For all these reasons the proportion of false-negative diagnoses and sensitivity cannot be determined. However, if there has been no selection of cases, the diagnostic sensitivity of different criteria in various conditions can be and has been compared. Catheterization data have been used for infarct localization (McConahay et al., 1970), but with diffuse arteriographic disease, localization of infarction is only presumptive. Various clinical methods have been used to circumvent this difficulty, e.g. use of generally accepted 12-lead criteria (Eddleman and Pipberger, 1971) or the time sequence of evolutionary changes in relation to the history and investigations (Young and Williams, 1968; Goldberger, 1945). We have analysed our results by these methods, but they are open to criticism and the results did not affect our conclusions.

The electrocardiogram may be normal in the presence of infarction, and may vary from day to day; therefore no criterion can be absolutely specific or sensitive (Cawood et al., 1974a, b; Willems, Poblete, and Pipberger, 1972). The results of this study suggest that diagnostic sensitivity for myocardial infarction and ventricular conduction defects is usually improved by 15-lead hybrid criteria and that the computer statement of probable or definite infarction corresponds satisfactorily with the actual diagnosis.

Superior forces for $\geqslant 30 \mathrm{~ms}$ and clockwise inscription of the first 25 to $30 \mathrm{~ms}$ in the frontal plane have been proposed as sensitive criteria for inferior infarction (McConahay et al., 1970; Young and Williams, 1968; Hugenholtz, Forkner, and Levine, 1961; Murata et al., 1967). It has been suggested that the vectorcardiographic appearance of inferior infarction is preserved in the presence of left anterior hemiblock (Kulbertus et al., 1971). However, this study suggests that vectorcardiographic criteria are no more sensitive than 12-lead 
criteria. Vector loops may vary considerably and the initial inscription is affected by the later direction of the QRS; clockwise rotation may occur without infarction if there is a vertical axis $\left(\geqslant+45^{\circ}\right)$ and inferior infarction may occur with counterclockwise rotation, particularly with left axis deviation (Gunnar et al., 1967), and sometimes with left anterior hemiblock. A $Q / R$ ratio $\geqslant 25$ per cent in aVF may be the best single discriminating factor between normal hospital patients and patients with inferior infarction (Simonson, 1961). Increasing duration of the $Q$ wave increases specificity (Myers, Klein, and Hiratzka, 1949), and a Q wave duration $>0.04 \mathrm{~s}$ in aVF is the next most accurate single-lead criterion (Simonson, 1961). However, combinations of leads have not been tested adequately.

Specific vectorcardiographic appearances in the horizontal plane have been described for anterior infarction (Hugenholtz et al., 1963), and it has been thought that these remain specific in the presence of left ventricular hypertrophy. Our results and those of others (Kini, Eddleman, and Pipberger, 1970) conflict with this view. All criteria of anterior infarction were less specific in the presence of left ventricular hypertrophy; the vectorcardiographic and orthogonal criteria were less specific than the $\mathrm{V}$ lead criteria, though $\mathrm{QS}$ waves in V1 and V2 and sometimes also in V3 were frequent findings in uncomplicated left ventricular hypertrophy.

The diagnosis of inferior or anterior infarction cannot be made by usual criteria in the presence of left bundle-branch system block because of frequent false-positive results. Moreover, left bundle- branch system block may conceal the changes of anterior and inferior infarction (Luy, Bahl, and Massie, 1973). The diagnosis of left anterior hemiblock did not appear to influence the diagnosis of inferior or anterior infarction. Though it has been pointed out that the changes of inferior infarction and anteroseptal infarction may be modified by left anterior hemiblock as a result of inferior direction of the initial $20 \mathrm{~ms}$ forces, this does not seem of great importance. In our experience, right bundlebranch system block has little effect on the diagnosis of inferior and anterior infarction, in contrast with the findings of Goldman and Pipberger (1969). Occasionally there was an increase in the initial anterior $20 \mathrm{~ms}$ forces in patients with infarction who developed right bundle-branch system block, even if there were V-lead electrocardiographic evidence of anterior infarction on the previous tracing. This increase of anterior forces might occasionally obscure anterior infarction or suggest true posterior infarction, and should be suspected if there is clockwise rotation of the vector loop in the horizontal plane. In conclusion, criteria which are used for the diagnosis of inferior and anterior infarction have been arranged in order of increasing sensitivity and decreasing specificity in Table 6.

Many factors influence $S T$ and $T$ wave changes (Varriale, Alfenito, and Kennedy, 1966), and we, therefore, do not use them for left ventricular hypertrophy diagnostic logic. This study indicated that the diagnosis of left ventricular hypertrophy was not supported by the presence of intraventricular conduction defect or delayed intrinsicoid deflection as was suggested by Estes (1966), though

TABLE 6 Diagnostic criteria for a computer system*

Inferior infarctiont

1) Q II, III, and aVF (or $Y$ ) $\geqslant 0.2 \mathrm{mV}$ and $\geqslant 25 \%$ of $\mathrm{R}$ wave

2) Q II, III, and aVF (or $Y$ ) $\geqslant 0.1 \mathrm{mV}$ and $\geqslant 25 \%$ of $R$ wave

3) $\mathrm{Q}$ II and $\mathrm{aVF}$ (or $\mathrm{Y}$ ) $\geqslant 0.2 \mathrm{mV}$ and $\geqslant 25 \%$ of $\mathrm{R}$ wave

4) $\mathrm{Q}$ III, and $\mathrm{aVF}$ (or $\mathrm{Y}$ ) $\geqslant 0.2 \mathrm{mV}$ and $\geqslant 25 \%$ of $\mathrm{R}$ wave and $Q$ II $\geqslant 0.2 \mathrm{mV}$

5) $\mathrm{Q}$ II and $\mathrm{aVF}$ (or $\mathrm{Y}$ ) $\geqslant 0.2 \mathrm{mV}$ only and $\mathrm{Q}$ III $\geqslant 0.2 \mathrm{mV}$ and $\geqslant 25 \%$ of $R$ wave

6) $\mathrm{Q}$ II, III, and aVF (or $\mathrm{Y}$ ) $\geqslant 0.2 \mathrm{mV}$ only

7) $\mathrm{Q}$ II $\geqslant 0.2 \mathrm{mV}$ only, $\mathrm{Q}$ aVF (or $\mathrm{Y}$ ) $\geqslant 0.2 \mathrm{mV}$ and $\geqslant 25 \%$ of $\mathrm{R}$ wave

8) Q II, III, and aVF (or Y) $\geqslant 0.2 \mathrm{mV}$ only

9) $Q$ III and aVF $\geqslant 0.2 \mathrm{mV}$ only

10) $\mathrm{Q}$ aVF $\geqslant 0.2 \mathrm{mV}$ only

11) Superior forces for $\geqslant 30 \mathrm{~ms}$ in frontal plane of VCG
Anterior infarction $\dagger$
1) Q V2, V3, and V4
2) Q V3 and V4
3) $Q R$ V2 and V3
4) QR V4
5) QR V3
6) QR V2
7) QS V2 and V3
8) QS V3
9) QS V2
10) $Q$ V2 or $V 3$
11) $\mathrm{Q} V 2$ or $\mathrm{V} 3$ or $\mathrm{V} 4$
12) First $20 \mathrm{~ms}$ forces posterior in horizontal and sagittal planes of VCG
13) $Q$ in $Z<10 \%$ of $R$ wave

*Criteria are arranged in order of increasing specificity and decreasing sensitivity from below upwards.

$t Q$ waves all of $\geqslant 30 \mathrm{~ms}$ for inferior infarction and $Q$ waves all of $\geqslant 20 \mathrm{~ms}$ in $\mathrm{V}$ leads for anterior infarction. 
in patients under 37 years of age, in whom multiple disorders are uncommon, such criteria might be of value. The gradual slope of ST depression from a normal $\mathrm{J}$ point to a wholly inverted $\mathrm{T}$ wave or an initially inverted $T$ wave, often with a terminal upright $T$ wave in anterolateral leads, is more typical of left ventricular hypertrophy than of ischaemia, but such appearances are difficult to quantify and may be misleading. Repolarization changes particularly in the frontal plane may be the result of left anterior hemiblock (Gomes, Lima, and Romalhao, 1975). Descriptive statements about ST segment deviation and $T$ wave inversion were issued by the computer and were clinically useful; only if there are pronounced ST segment changes can they be used to support a diagnosis of infarction.

Description of ST and T wave changes forms an important part of an electrocardiographic report. Because of the lack of sensitivity of our orthogonal lead criteria for ST and $T$ wave changes and measurement errors, false-negative interpretation may occur. Though it is possible that better criteria could be devised, the criteria used had been found to produce the most acceptable number of false-positive and false-negative results. Further criteria based on the orthogonal leads and vectorcardiographic $T$ wave loops may be of value when data from such loops have been quantified satisfactorily, but so far we have had little success with simple angular criteria. A 12-lead electrocardiogram may appear to reduce criteria errors to a satisfactory level, but the use of 15 leads with hybrid 'or-logic' reduces false-negative measure- ment errors and increases sensitivity of diagnosis; this increases false-positive results, and necessitates further hybrid 15-lead 'and-logic' so that more definite $T$ wave statements can be made.

At present it is impossible to report quantitative levels of probability, since though the range of electrocardiographic measurements for the population is known, it is necessary to have these from cases with all the diagnoses causing false-positive and false-negative computer reports. It is often difficult to reach a final diagnosis in life, particularly if there are multiple abnormalities, but such diagnoses must be made if the reference source of confirmed diagnoses is to be as unselected as possible. For example, patients with old infarction (and these were mostly 'probable infarctions'; see Appendix B) fulfilled fewer electrocardiographic criteria for infarction; multiple infarctions may conceal individual infarction criteria. All these cases must be included in the reference source if valid estimates of numerical probability are to be given for any diagnosis. Less common conditions, such as right ventricular hypertrophy and emphysema, may complicate such logic.

In Table 7 the optimal lead systems for various diagnoses are presented, based on our current results (Talbot et al., 1973). Left ventricular hypertrophy voltage criteria provide a good example of the value of multiple lead systems since no single system is sufficiently sensitive without producing excessive false-positive results. In isolation the vectorcardiographic criteria of left ventricular hypertrophy were more specific yet as sensitive as the V-lead criteria of left ventricular hyper-

TABLE 7 Requirements for computer-aided electrocardiogram system

$\begin{array}{lll}\text { 12-lead criteria } & \begin{array}{l}\text { Frank 3-lead and vector- Hybrid 15-lead criteria } \\ \text { cardiographic criteria }\end{array}\end{array}$

cardiographic criteria

Axis, hemiblocks

Right bundle-branch system block (complete and incomplete)

Anterior ischaemia

Non-specific abnormalities of ST-T wave

Specific diagnosis of anterior infarction

Sensitive diagnosis of anterior infarction

Sensitive diagnosis of left ventricular hypertrophy

Right ventricular hypertrophy

infarction
Specific diagnosis of anterior infarction ('and-logic')

Specific diagnosis (and-logic) and sensitive diagnosis (or-logic) of inferior infarction

Left bundle-branch system block

Marginal improvements in specific ('and-logic') and sensitive ('or-logic') diagnoses of ischaemia and left ventricular hypertrophy

Specific diagnosis of left ventricular hypertrophy

Anterolateral ischaemia

Inferior ischaemia

Lateral infarction 
trophy. The most specific criteria were the limb lead criteria of Sokolow and Lyon (1949) with adjustments for the normal limits of QRS voltage that can be expected from axis changes.

We believe that a 15-lead system with hybrid logic does produce better results than either a 12lead or a 3-lead orthogonal system used alone. A Frank orthogonal system alone does not seem satisfactory for hospital practice though a 12-lead system alone might be sufficient. Multiple leads with vectorcardiographic display are complementary and for optimal diagnosis by a computer electrocardiographic system may be preferred. Other systems of orthogonal leads or praecordial leads may be superior, but redundancy of information will always be important. For diagnostic sensitivity we prefer to combine the 15-lead system and vectorcardiogram with 'or-logic', and for specificity we prefer 'and-logic'. This study has shown that criteria for the diagnosis of infarction and also for the diagnosis of left ventricular hypertrophy or ischaemia are influenced by the presence or absence of other electrocardiographic abnormalities and appropriate weighting should be included in the programme. When clinical information is stored alongside the electrocardiogram, this information may also be used.

\section{References}

Allenstein, B. J., and Mori, H. (1960). Evaluation of electrocardiographic diagnosis of ventricular hypertrophy based on autopsy comparison. Circulation, 21, 401.

Blackburn, H., Keys, A., Simonson, E., Rautaharju, P., and Punsar, S. (1960). The electrocardiogram in population studies: a classification system. Circulation, 21, 1160.

Bonner, R. E., Crevasse, L., Ferrer, M. I., and Greenfield, J. C., Jr. (1972). A new computer program for analysis of scalar electrocardiograms. Computers and Biomedical Research, 5, 629.

Borun, E. R., Chapman, J. M., and Massey, F. J. (1966). Computer analysis of Frank lead electrocardiographic data recorded in an epidemiologic study. American fournal of Cardiology, 18, 664.

Caceres, C. A., and Hochberg, H. M. (1970). Performance of the computer and physician in the analysis of the electrocardiogram. American Heart fournal, 79, 439.

Cawood, H. T., MacFarlane, P. W., Hillis, S., and Lawrie, T. D. V. (1974a). Day to day and beat to beat variation in normal 3 orthogonal lead electrocardiograms. British Heart Fournal, 36, 1225.

Cawood, H. T., Hillis, S., MacFarlane, P. W., and Lawrie, T. D. V. (1974b). Day to day variation in 3 orthogonal lead electrocardiogram parameters after acute myocardial infarction. British Heart fournal, 36, 1231.

Chou, T. C., and Helm, R. A. (1967). Clinical Vectorcardiography. Grune and Stratton, New York.

Cornfield, J., Dunn, R. A., Batchelor, C. D., and Pipberger, H. V. (1973). Multigroup diagnosis of electrocardiograms. Computers and Biomedical Research, 6, 97.

Davies, L. G. (1958). Observer variation in reports on electrocardiograms. British Heart fournal, 20, 153.
Eddleman, E. E., and Pipberger, H. V. (1971). Computer analysis of the orthogonal electrocardiogram and vectorcardiogram in 1002 patients with myocardial infarction. American Heart fournal, 81, 608.

Estes, E. (1966). Left ventricular hypertrophy. In The Heart, Arteries and Veins, pp. 137-140. Ed. by J. W. Hurst and R. B. Logue. McGraw Hill, New York.

Goldberger, E. (1945). The differentiation of normal from abnormal Q waves. American Heart fournal, 30, 341.

Goldman, M. J., and Pipberger, H. V. (1969). Analysis of the orthogonal electrocardiogram and vectorcardiogram in ventricular conduction defects with and without myocardial infarction. Circulation, 39, 243.

Gomes, M. C., Lima, C. A., and Romalhao, (1975). Repolarisation changes in LAH. A review. Advances in Cardio$\log y, 14,148$.

Gunnar, R. M., Pietras, R. J., Blackaller, J., Dadmun, S. E., Szanto, P. B., and Tobin, J. R. (1967). Correlation of vectorcardiographic criteria for myocardial infarction with autopsy findings. Circulation, 35, 158.

Hugenholtz, P. G., Forkner, E. C., Jr., and Levine, H. D. (1961). A clinical appraisal of the vectorcardiogram in myocardial infarction. II. The Frank system. Circulation, 24, 825.

Hugenholtz, P. G., Ryan, T. J., Woerner, T., and Levine, H. D. (1963). Recognition of anterior wall infarction in patients with left ventricular hypertrophy. A study of the Frank vectorcardiogram. Circulation, 27, 386.

Kini, P. M., Eddleman, E. E., and Pipberger, H. V. (1970). Electrocardiographic differentiation between left ventricular hypertrophy and anterior myocardial infarction. Circulation, 42, 875.

Kulbertus, H. E., Collignon, P., Humblet, L., and DelevalRutten, F. (1971). Left axis deviation in inferior infarction; vectorcardiographic recognition of concomitant left anterior hemiblock. Chest, $60,362$.

Luy, G., Bahl, O. P., and Massie, E. (1973). Intermittent left bundle branch block: a study of the effects of left bundle branch block on the electrocardiographic patterns of myocardial infarction and ischemia. American Heart Fournal, 85, 332.

McConahay, D. R., McCallister, B. D., Hallermann, F. J., and Smith, R. E. (1970). Comparative quantitative analysis of the electrocardiogram and vectorcardiogram: correlations with the coronary arteriogram. Circulation, 42, 245.

MacFarlane, P. W., Lorimer, A. R., and Lawrie, T. D. V. (1971). 3 and 12 lead electrocardiogram interpretation by computer: a comparison on 1093 patients. British Heart fournal, 33, 266.

Murata, K., Kurihara, H., Matsushita, S., Terasawa, F., Ikeda, M., and Seki, M. (1967). Usefulness and reliability of vectorcardiography in the diagnosis of myocardial infarction. A vectorcardiographic and pathological correlation. Fapanese Heart Fournal, 8, 522.

Myers, G. B., Klein, H. A., and Hiratzka, T. (1949). Correlation of electrocardiographic and pathologic findings in posterior infarction. American Heart fournal, 38, 547.

Pipberger, H. V., Bialek, S. M., Perloff, J. K., and Schnaper, H. W. (1961). Correlations of clinical information in the standard 12-lead ECG and corrected orthogonal 3-lead ECG. American Heart Fournal, 61, 34.

Pordy, L., Jaffe, H., Chesky, K., Friedberg, C. K., Fallowes, L., and Bonner, R. E. (1968). Computer diagnosis of electrocardiograms. IV. A computer program for contour analysis with clinical results of rhythm and contour interpretation. Computers and Biomedical Research, 1, 408.

Rosenbaum, M. B. (1969). Types of left bundle branch block and their clinical significance. Fournal of Electrocardiology, 2, 197. 
Scheinok, P., Dreifus, L. S., Thum, K. W., Reich, M. B., and Krazesky, A. (1972). Computer-aided ECG analysis and research in clinical setting. fournal of Electrocardiology, 5 (4), 377.

Simonson, E. (1961). Differentiation Between Normal and Abnormal in Electrocardiography, pp. 35-41. C. V. Mosby, St. Louis.

Smith, R. E., and Hyde, C. M. (1969). Computer analysis of the electrocardiogram in clinical practice. In Electrical Activity of the Heart, pp. 305-322. Ed. by G. W. Manning and S. P. Ahuja. Charles C. Thomas, Springfield, Illinois.

Sokolow, M., and Lyon, T. P. (1949). The ventricular complex in left ventricular hypertrophy as obtained by unipolar precordial and limb leads. American Heart fournal, 37, 161.

Sotobata, I., Richman, H., and Simonson, E. (1970). Recognition of myocardial infarction by means of Frank lead Q/R ratios. American Heart fournal, 79, 508.

Talbot, S., Dreifus, L. S., Watanabe, Y., Chiang, R., Morris, K., and Reich, M. (1974). Normal measurements of modified Frank corrected orthogonal electrocardiograms and their importance in an on-line computer-aided electrocardiographic system. British Heart fournal, 36, 475.
Talbot, S., Dreifus, L. S., Watanabe, Y., Reich, M., Chiang, R., and Morris, K. (1973). Diagnostic accuracy of a 15-lead hybrid computer-aided electrocardiographic system. European fournal of Cardiology, 1, 29.

Varriale, P., Alfenito, J. C., and Kennedy, R. J. (1966). The vectorcardiogram of left ventricular hypertrophy: analysis and criteria. (Frank lead system). Circulation, 33, 569.

Willems, J. L., Poblete, P. F., and Pipberger, H. V. (1972). Day-to-day variation of the normal orthogonal electrocardiogram and vectorcardiogram. Circulation, 45, 1057.

Yano, K., and Pipberger, H. V. (1964). Correlations between radiographic heart size and orthogonal electrocardiograms in patients with left ventricular overload. American Heart fournal, 67, 44.

Young, E., and Williams, C. (1968). The frontal plane vectorcardiogram in old inferior myocardial infarction. Criteria for diagnosis and electrocardiographic correlation. Circulation, 37, 604.

Requests for reprints to Dr. Stephen Talbot, Department of Clinical Cardiology, Hammersmith Hospital, Du Cane Road, London W12 0HS.

\section{APPENDIX A}

\begin{tabular}{|c|c|c|c|}
\hline & 12-lead & Frank 3-lead & Diagnosis \\
\hline \multicolumn{4}{|c|}{ Hybrid logic for inferior infarction } \\
\hline 1) & $\begin{array}{l}\mathrm{Q} \text { wave of } \geqslant 0.2 \mathrm{mV} \text { and } \geqslant 30 \mathrm{~ms} \text { in II, } \\
\text { III, and aVF }\end{array}$ & - & Inferior infarction \\
\hline 2) & $\begin{array}{l}\mathrm{Q} \text { wave of } \geqslant 0.2 \mathrm{mV} \text { and } \geqslant 30 \mathrm{~ms} \text { in any } \\
2 \text { leads of II, III, and aVF }\end{array}$ & $\begin{array}{l}Q \text { in } Y \geqslant 0.1 \mathrm{mV} \text { or } Q / R \text { ratio } \\
\text { in } Y \geqslant 0.2\end{array}$ & Inferior infarction \\
\hline 3) & $\begin{array}{l}Q \text { wave of } \geqslant 0.2 \mathrm{mV} \text { in any } 2 \text { leads of II, III, } \\
\text { and aVF or } Q \text { wave of } \geqslant 0.1 \mathrm{mV} \text { and } \geqslant 30 \mathrm{~ms} \\
\text { in } 2 \text { leads of II, III, and aVF }\end{array}$ & $\begin{array}{l}\text { Superior forces } \geqslant 30 \mathrm{~ms} \text { in frontal } \\
\text { plane VCG }\end{array}$ & Possible inferior infarction \\
\hline 4) & 一 & $\begin{array}{l}Q / R \text { ratio in } Y \geqslant 0.25 \text { and } Q \text { wave } \\
\quad \geqslant 30 \text { ms duration }\end{array}$ & Possible inferior infarction \\
\hline 5) & $\begin{array}{l}\mathrm{Q} \text { duration } \geqslant 0.1 \mathrm{mV} \text { and } \geqslant 20 \mathrm{~ms} \text { in any } 2 \\
\text { leads of II, III, and aVF (if QRS axis } \\
>+60^{\circ} \text { ) }\end{array}$ & $\begin{array}{l}Q / R \text { ratio in } Y \geqslant 0.2 \text { and } Q \text { wave } \\
\geqslant 20 \mathrm{~ms} \text { duration }\end{array}$ & $\begin{array}{l}\text { Possible inferior wall } \\
\text { infection }\end{array}$ \\
\hline \multicolumn{4}{|c|}{ Hybrid logic for anterior infarction $\star$} \\
\hline 1) & $\begin{array}{l}\text { 12-lead } \\
\text { No } R \text { wave in V1 and V2 and V3, or V3 and } \\
\text { V4, or V4 and V5 }\end{array}$ & $\begin{array}{l}\text { Frank 3-lead } \\
\text { - }\end{array}$ & $\begin{array}{l}\text { Diagnosis } \\
\text { Anterior infarction }\end{array}$ \\
\hline 2) & & Absent $Q$ in $Z$ & Possible anterior infarction \\
\hline 3) & $\begin{array}{l}\mathrm{R} \text { in V2 and V3 or V3 and V4, or V4 and } \\
\mathrm{V} 5 \leqslant 0.1 \mathrm{mV}\end{array}$ & $\begin{array}{l}\mathrm{Q} / \mathrm{R} \text { ratio in } \mathrm{Z}<0 \cdot 1 \dagger \\
\text { or } 20 \mathrm{~ms} \text { initial forces do not enter } \\
+90^{\circ} \text { to }-90^{\circ} \text { in sagittal plane and } \\
0^{\circ} \text { to }+180^{\circ} \mathrm{m} \text { horizontal plane VCG }\end{array}$ & Possible anterior infarction \\
\hline 4) & $R$ in $V 2$ and $V 3 \leqslant 0.3 \mathrm{mV}$ & $\begin{array}{l}\text { No anterior forces in horizontal and } \\
\text { sagittal planes }\end{array}$ & $\begin{array}{l}\text { Possible anterior wall } \\
\text { infarction }\end{array}$ \\
\hline
\end{tabular}

„'And-logic' requires the 12-lead criterion and either the orthogonal or vectorcardiographic criterion. 'Or-logic' requires either 12 -lead criterion or an orthogonal criterion or a vectorcardiographic criterion.

$\dagger$ Note $Q / R$ ratio in $Z$ only measured if $R$ in $Z>0.5 \mathrm{mV}$. 


\section{APPENDIX B}

Definite myocardial infarction

1) History of increasing angina pectoris and pain for $\geqslant 2$ hours at rest plus

2) Serial AST, LDH, and CK elevation plus

3) Elevation of ESR or white blood count

4) Coronary arteriographic evidence of occlusion and history of infarction or necropsy confirmation

Probable myocardial infarction

1) History of increasing angina pectoris plus

2) Final diagnosis of recent or old myocardial infarction

Definite left ventricular hypertrophy

1) Precipitating factor: at least one of the following:

a) Diastolic blood pressure $>90 \mathrm{mmHg}$ on 3 or more occasions

b) Diastolic blood pressure $>100 \mathrm{mmHg}$ on 2 occasions

c) Aortic valve disease or mitral regurgitation

d) History of hypertension in the past and 1 recording of $>90 \mathrm{mmHg}$ diastolic plus at least one of the following:

2) a) Severe cardiomegaly clinically or radiographically

b) Confirmation of suspected lesion by cardiac catheterization

3) Evidence of left ventricular hypertrophy or valvular lesion at surgery or necropsy

Probable left ventricular hypertrophy

1) As above

plus

2) Moderate cardiomegaly radiographically or clinically

or

3) Past history of hypertension or known valvular lesion for at least 5 years

Abbreviations: AST-serum aspartate aminotransferase. LDH-serum lactic acid dehydrogenase. CK-creatine kinase. 